\title{
Spray cooling by multi-walled carbon nanotubes and Fe nanoparticles
}

\author{
H. Bellerová \& M. Pohanka \\ Heat Transfer and Fluid Flow Laboratory, Faculty of Mechanical \\ Engineering, Brno University of Technology, Czech Republic
}

\begin{abstract}
An experimental investigation of spray cooling performed with water based nanofluid containing multi-walled carbon nanotubes and $\mathrm{Fe}$ nanoparticles was carried out. The concentrations of carbon nanotubes in the liquid used in the experimental program were $1 \mathrm{wt} . \%, 0.1 \mathrm{wt} . \%, 0.01 \mathrm{wt} . \%$, the concentrations of $\mathrm{Fe}$ nanoparticles were $40 \mathrm{wt} . \%, 10 \mathrm{wt} . \%, 1 \mathrm{wt} . \%$. The liquid was sprayed on the surface by a full cone nozzle from distances of 40,100 and $160 \mathrm{~mm}$ with flow rates of 1 to $2 \mathrm{~kg} / \mathrm{min}$ (liquid impingement densities of 1 to $40 \mathrm{~kg} / \mathrm{m}^{2} \mathrm{~s}$ ). A steel sensor measuring temperature history was cooled by spraying from $190{ }^{\circ} \mathrm{C}$. The heat transfer coefficient was calculated at an interval of the surface temperature from $100{ }^{\circ} \mathrm{C}$ to $50^{\circ} \mathrm{C}$ by inverse modelling, and compared with the heat transfer coefficient of water cooling. Using Fe nanoparticles showed a decrease of the heat transfer coefficient on the cooled surface. The majority of experiments with carbon nanotubes also showed a decrease of the heat transfer coefficient. However, there were some conditions during which an increase was observed.
\end{abstract}

Keywords: nanofluids, multi-walled carbon nanotubes, Fe nanoparticles, heat transfer, spray cooling, experimental.

\section{Introduction}

It was anticipated that some fluid heat qualities would be improved by adding metal parts, metal oxides parts, or generally those parts from materials which have suitable heat transfer characteristics. Some attempts focused on cooling were made by liquid additives in water, with particles sized in $\mathrm{mm}$ or $\mu \mathrm{m}$ mixed into the fluids and with nanofluids. Nanofluid is a suspension of fluid (water, ethylene glycol, oil, bio-fluids, polymer solution, etc.) and particles (metals, 
metal oxides, nonmetals as carbon nanotubes, etc.) sized 1-100 nm. Not many works of research have been focused on the cooling intensity by nanofluids and very few on the cooling intensity during spray cooling (e.g. Chakraborty et al. [1], Bansal and Pyrtle [2]).

\subsection{Thermal conductivity of nanofluids with carbon nanotubes}

Research shows that the thermal conductivity of nanofluid is higher than that of base fluid. The first group of researchers who studied thermal conductivity of nanofluid with carbon nanotubes was Choi et al. [3]. They used oil with 1 vol.\% of multi-walled nanotubes sized $25 \mathrm{~nm}$ in diameter and $50 \mu \mathrm{m}$ in length and discovered an enhancement of $160 \%$. A large number of scientists showed a keen interest in the use of carbon nanotubes, yet they did not confirm this significant enhancement of thermal conductivity by adding carbon nanotubes. The enhancement of thermal conductivity at room temperature was in the majority of the research that followed (e.g. Assael et al. [4], Amrollahi et al. [5]) $20-40 \%$ by adding less than 3 vol. $\%$ carbon nanotubes to some fluid like water, synthetic engine oil or ethylene glycol.

\subsection{Thermal conductivity of nanofluids with Fe nanoparticles}

The thermal conductivity of $\mathrm{Fe}_{3} \mathrm{O}_{4}$ nanoparticles in water was studied by Zhu et al. [6] and an enhancement of 38\% was observed for their concentration of 4 vol.\%. This enhancement was more than for other oxide aqueous nanofluids. Hong et al. [7] investigated $0.1-0.55$ vol.\% of Fe nanoparticles sized $10 \mathrm{~nm}$ in ethylene glycol. The enhancement was $18 \%$.

\subsection{Heat transfer characteristics of nanofluids with carbon nanotubes and Fe nanoparticles}

According to the aforementioned information about thermal conductivity of carbon nanotubes and Fe nanoparticles, the nanofluids should be a suitable coolant and a majority of scientists really found an increase in the heat transfer coefficient by using carbon nanotubes and Fe nanoparticles. In the work of Ding et al. [8] the convective heat transfer of $0.5 \mathrm{wt} . \%$ of carbon nanotubes in water was enhanced by over 350\%. According to Liao and Liu [9], the enhancement ratio of heat transfer coefficient was $18-25 \%$ for 2 wt. $\%$ and $49-56 \%$ for $1 \mathrm{wt} . \%$ at $58{ }^{\circ} \mathrm{C}$. Park and Jung [10] found that there was an increase of up to $30 \%$ in the nucleate boiling heat transfer of 1 vol.\%. Unlike the findings of Park et al. [11], concluded that the pool boiling heat transfer coefficient of aqueous suspension with $0.0001-0.5$ vol. $\%$ of carbon nanotubes was lower than that of pure water. Shi et al. [12] studied the pool boiling heat transfer of Fe nanoparticles sized $26 \mathrm{~nm}$ in water and found that the enhancement was up to $60 \%$. 


\subsection{Spray cooling by nanofluids}

To date limited research on the heat transfer of nanofluid with carbon nanotubes or with Fe nanoparticles by spray cooling has been conducted. There are some papers about heat transfer by spray cooling with other nanofluids. Bansal and Pyrtle [2] examined alumina nanoparticles dispersed in water in concentrations of 0.25 to $0.505 \mathrm{wt} . \%$. The initial temperature of the surface was $150{ }^{\circ} \mathrm{C}$ and the surface was cooled to $75^{\circ} \mathrm{C}$. The cooling intensity was comparable to the cooling intensity of water. Chakraborty et al. [1] used 0.1 wt. $\% \mathrm{TiO}_{2}$ in water to cool a plate heated up to $1200{ }^{\circ} \mathrm{C}$. A significant enhancement in the cooling rate was observed.

\section{Basic properties of examined nanofluids}

The nanofluid with 1 wt.\% carbon nanotubes was produced by the Belgian company Nanocyl S.A. The nanofluid with 40 wt.\% of Fe nanoparticles was offered by prof. Miroslav Mašlán from Palacky University Olomouc. In the experiments, the concentrations of $0.1 \mathrm{wt} . \%$ and $0.01 \mathrm{wt} . \%$ of carbon nanotubes and the concentrations of $10 \mathrm{wt} . \%$ and $1 \mathrm{wt} . \%$ of Fe nanoparticles were achieved by diluting the original concentrations with distilled water. Both the density of nanofluids and the specific heat were measured. A calorimeter "Kalorymetr KL-5" was used to measure the specific heat capacity.

\subsection{Properties of nanofluid with carbon nanotubes}

The nanofluid with carbon nanotubes is a black and odorless aqueous dispersion with $1 \mathrm{wt} . \%$ of carbon nanotubes (0.5-1.5 wt.\%). The length of multi-walled carbon nanotubes was $1.3 \mu \mathrm{m}$ and the diameter $9 \mathrm{~nm}$ on average (fig. 1). The nanoparticles were prepared by catalytic carbon vapor deposition. The nanofluid
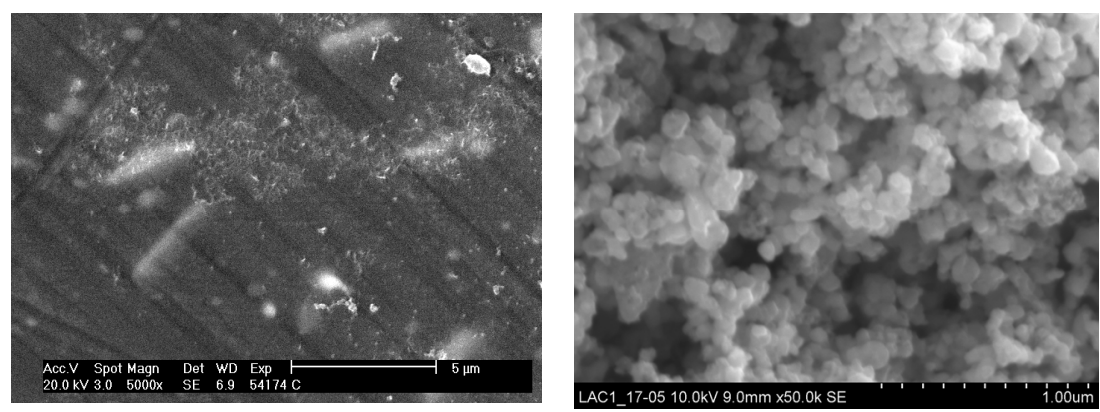

Figure 1: The left picture: cluster of carbon nanotubes (photo by Institute of Material Science, Brno University of Technology); the right picture: $\mathrm{Fe}$ nanoparticles (photo from prof. Miroslav Mašlán̆, Palacky University, Olomouc). 
also contained an ionic surfactant in a concentration of $0.1-3 \mathrm{wt} \%$. The specific

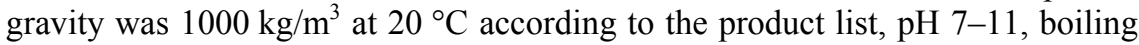
point $100{ }^{\circ} \mathrm{C}$. It is usually used for waterborne systems for antistatic coatings, transparent films, and cleaning rooms. The densities of $1 \mathrm{wt} . \%, 0.1 \mathrm{wt} . \%$ and 0.01 wt. $\%$ of carbon nanotubes were $1011 \mathrm{~kg} / \mathrm{m}^{3}, 1004 \mathrm{~kg} / \mathrm{m}^{3}$ and $1002 \mathrm{~kg} / \mathrm{m}^{3}$ at room temperature. The specific heat was measured at $20-60{ }^{\circ} \mathrm{C}$ only for $1 \mathrm{wt} . \%$ of carbon nanotubes and it was $3763 \mathrm{~J} / \mathrm{kg} \mathrm{K}$.

\subsection{Properties of nanofluid with Fe nanoparticles}

The Fe nanoparticles were spherical and measured $80 \mathrm{~nm}$ on average (fig. 1). The nanofluid did not contain any stabilizers. The densities of $40 \mathrm{wt} . \%, 10 \mathrm{wt} \%$ and $1 \mathrm{wt} . \%$ of Fe nanoparticles were $1079 \mathrm{~kg} / \mathrm{m}^{3}, 1006 \mathrm{~kg} / \mathrm{m}^{3}$ and $1002 \mathrm{~kg} / \mathrm{m}^{3}$. The specific heat was $3528 \mathrm{~J} / \mathrm{kg} \mathrm{K}$ at $20-60{ }^{\circ} \mathrm{C}$ for $40 \mathrm{wt} . \%$ of nanoparticles.

\section{Experiment}

\subsection{Experimental plan}

The hot surface was sprayed by the full cone nozzle Lechler 460.443.17 CA with a spray angle of $45^{\circ}$ from three distances of $40 \mathrm{~mm}, 100 \mathrm{~mm}$, and $160 \mathrm{~mm}$. The flow rates of $1 \mathrm{~kg} / \mathrm{min}, 1.5 \mathrm{~kg} / \mathrm{min}$, and $2 \mathrm{~kg} / \mathrm{min}$ were steady during the experiment (the appropriate liquid impingement density is shown in Tab. 1). The initial experiments were conducted by spraying pure water and after that nanofluid. Finally, the nanofluid spray cooling intensity was compared with the pure water spray cooling intensity. The summary of experiments is shown in Tab. 1.

Table 1: $\quad$ Experimental plan.

\begin{tabular}{|c|c|c|c|c|c|}
\hline \multirow[t]{2}{*}{ Fluid } & Concentration & Nozzle & Distance & $\begin{array}{l}\text { Flow } \\
\text { rate }\end{array}$ & $\begin{array}{c}\text { Liquid } \\
\text { impingemen } \\
\mathrm{t} \text { density }\end{array}$ \\
\hline & wt. $\%$ & & $\mathrm{~mm}$ & $\mathrm{~kg} / \mathrm{min}$ & $\mathrm{kg} / \mathrm{m}^{2} \mathrm{~s}$ \\
\hline Pure water & 100 & \multirow{9}{*}{$\begin{array}{l}\text { Full } \\
\text { cone }\end{array}$} & \multirow{3}{*}{40} & 1 & 19.3 \\
\hline \multirow{4}{*}{$\begin{array}{l}\text { C nanotubes } \\
\text { in water }\end{array}$} & \multirow{4}{*}{$\begin{array}{c}1 \\
0.1 \\
0.01\end{array}$} & & & 1.5 & 29 \\
\hline & & & & 2 & 38.7 \\
\hline & & & \multirow{3}{*}{100} & 1 & 3.1 \\
\hline & & & & 1.5 & 4.6 \\
\hline \multirow{4}{*}{$\begin{array}{c}\mathrm{Fe} \\
\text { nanoparticles } \\
\text { in water }\end{array}$} & \multirow{4}{*}{$\begin{array}{c}40 \\
10 \\
1\end{array}$} & & & 2 & 6.2 \\
\hline & & & \multirow{3}{*}{160} & 1 & 1.2 \\
\hline & & & & 1.5 & 1.8 \\
\hline & & & & 2 & 2.4 \\
\hline
\end{tabular}




\subsection{The nozzle}

The liquid impingement density in Tab. 1 was determined theoretically by the type of nozzle (full cone), distance between nozzle and surface, spray angle and flow rates. The radius of impingement area should be $41.4 \mathrm{~mm}$ in distance $100 \mathrm{~mm}$ from the nozzle. Figure 2 shows the measured pressure of water falling from a distance of $100 \mathrm{~mm}$ for three flow rates. Figure 2 shows that the shape of spray was not a full cone for flow rate of $1 \mathrm{~kg} / \mathrm{min}$.

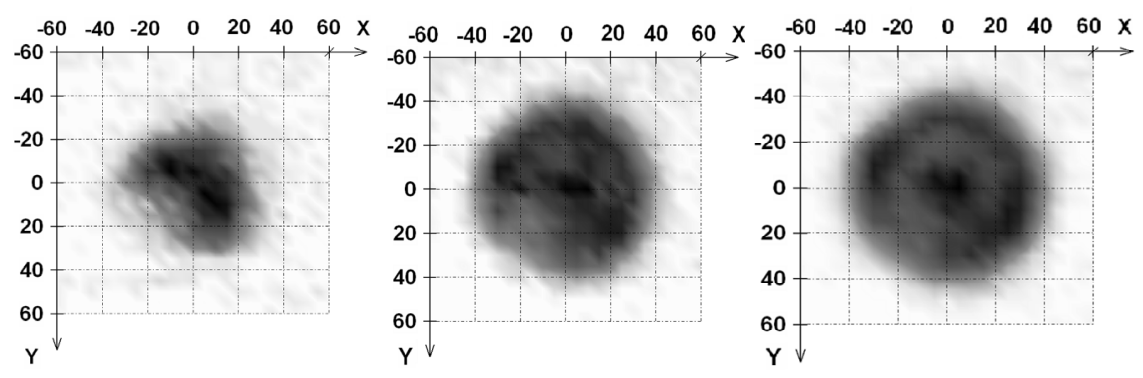

Figure 2: $\quad$ Measured pressure distribution of pure water spraying from full cone nozzle at a distance of $100 \mathrm{~mm}$, the pictures from left to right represent the flow rates $1 \mathrm{~kg} / \mathrm{min}, 1.5 \mathrm{~kg} / \mathrm{min}, 2 \mathrm{~kg} / \mathrm{min}$; the axis units are $\mathrm{mm}$; the darker the colour, the higher the pressure of water; the maximum value for $1 \mathrm{~kg} / \mathrm{min}$ was $112 \mathrm{~Pa}$, for $1.5 \mathrm{~kg} / \mathrm{min}$ $186 \mathrm{~Pa}$, for $2 \mathrm{~kg} / \mathrm{min} 297 \mathrm{~Pa}$.

\subsection{The cooled sensor}

The cooled sensor (fig. 3) was made from austenitic steel 314 AISI and built into Teflon. All surfaces excluding the cooled surface were protected against cooling. The thermocouple of type $\mathrm{K}$ with a diameter of $0.5 \mathrm{~mm}$ was soldered
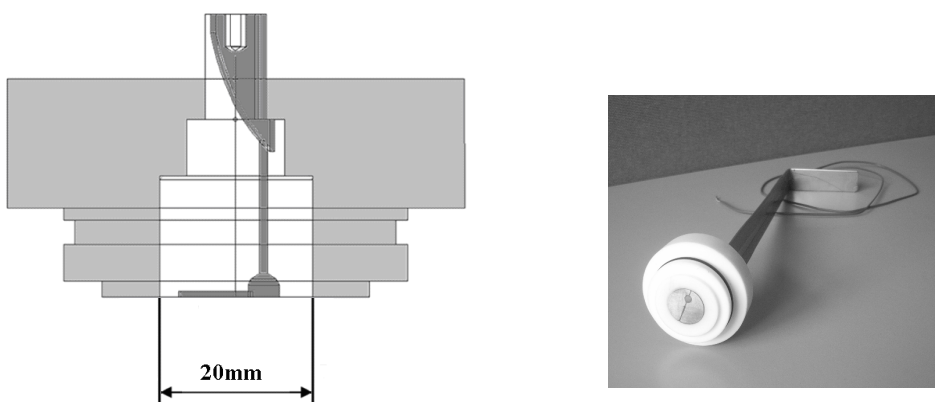

Figure 3: Cooled steel sensor; the drawing is on the left side (steel sensor body is colored white, Teflon is light grey, channel for thermocouple is dark grey); the photo is on the right side. 
into a cooled cylindrical steel sensor with a diameter of $20 \mathrm{~mm}$ and was placed parallel to the surface $0.37 \mathrm{~mm}$. The thermocouple was connected with a data logger, which is mobile equipment for recording data.

\subsection{Experiment description}

The steel sensor in Teflon was heated up to $190^{\circ} \mathrm{C}$ by an electrical furnace and was held at that temperature for 15 minutes then put into an experimental test bench (fig. 4) with the tested surface face down. A nozzle was placed under the probe. Before the experiment, the tested fluid was located in a pressure tank pressurized by nitrogen. The manometer was located close to the nozzle. After putting the sensor into the equipment, the fluid went through the nozzle and sprayed the cooled surface. The fluid was caught in the experimental equipment after spraying. At the end of the experiment, the fluid was moved again to the pressure tank. The measurement took tenths of seconds, and the sensor surface was cooled to approximately $30{ }^{\circ} \mathrm{C}$. During the experiment, the sensor temperature, coolant temperature and ambient temperature were measured. These data were saved by the data logger and downloaded to a computer after the test. Then they were used for an inverse calculation in a non-commercial program based on Pascal programming language. The output from the program was a physical quantity characterizing the cooling intensity.

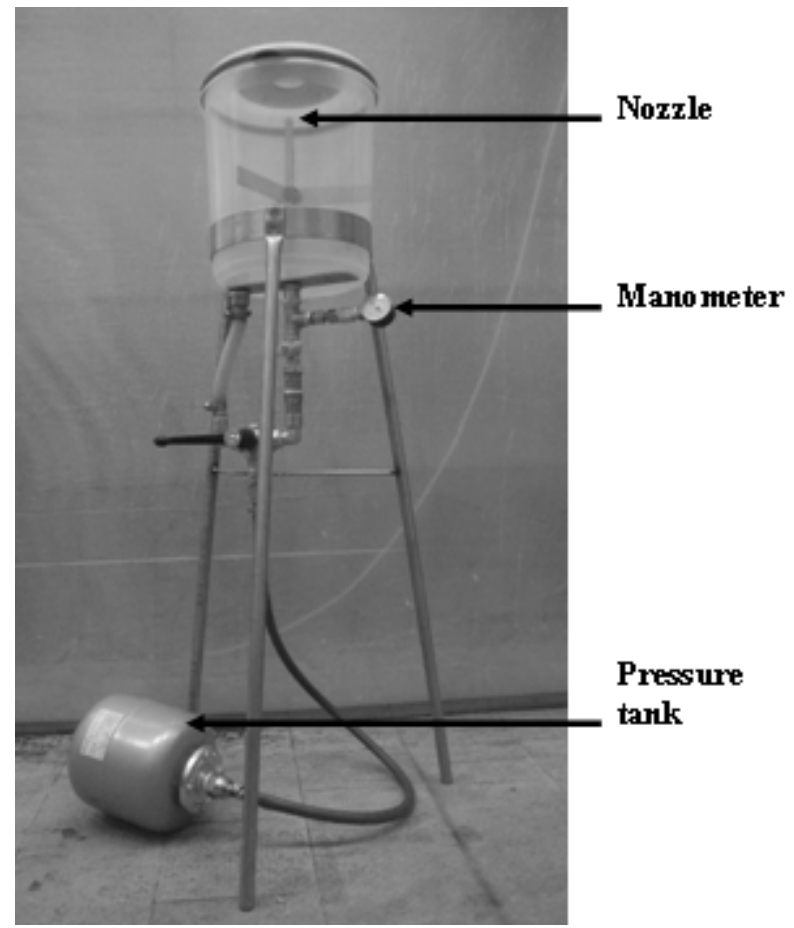

Figure 4: $\quad$ Experimental equipment. 


\section{Calculation of cooling intensity}

The cooling intensity is characterized by the heat transfer coefficient HTC $\left[\mathrm{W} / \mathrm{m}^{2} \mathrm{~K}\right]$. The Beck algorithm of one-dimensional inverse task [13] was applied to find the heat transfer coefficient. The direct task of the two-dimensional thermal field was a part of the inverse solution and was solved by using the finite difference method (fig. 5). The inverse task provides the surface temperature and the heat transfer coefficient history.
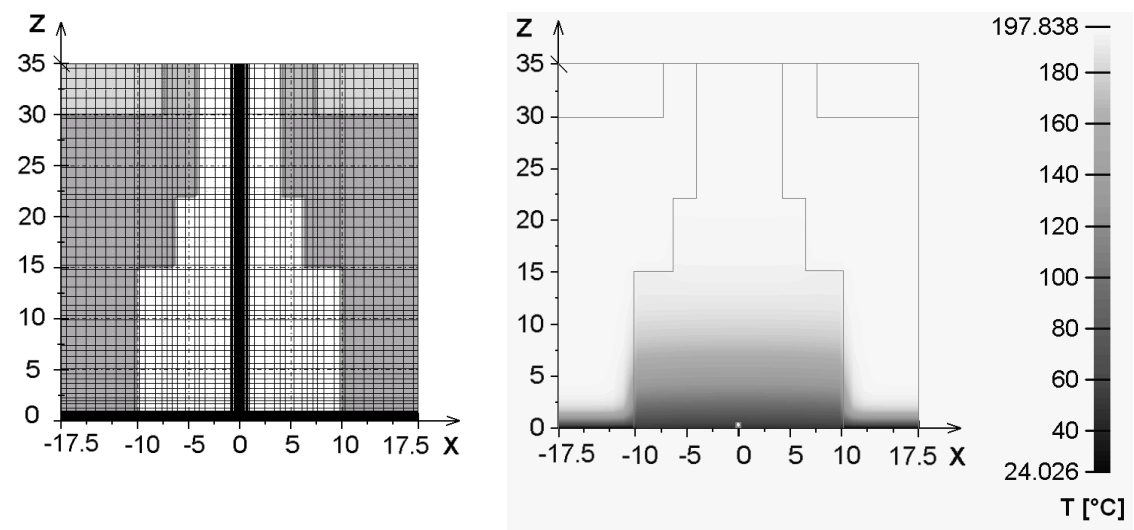

Figure 5: The picture on the left: control volumes covering model of steel body that were used for direct task (dark grey is for teflon, light grey for female screw, white for steel and for air around female screw); the picture on the right: the thermal field in cooled steel body after $5 \mathrm{~s}$ of cooling; the temperature of steel surface is $50{ }^{\circ} \mathrm{C}$, the axis units are in $\mathrm{mm}$.

\section{Results}

An example of record and results from the cooling experiment is shown in fig. 6 . The measured temperature history in thermocouple position, computed surface temperature and computed HTC is shown. Some fluctuations can be seen on the HTC curves in fig. 6 , it is the result of the random fluctuation of falling droplets in the impact area. The results for spraying with pure water were found to match the results published by Ciofalo et al. [14]. The temperature field in the whole steel sensor after $5 \mathrm{~s}$ of cooling is illustrated in fig. 5 .

The average results from the experiments described in this paper are shown in figs. 7-10. The average values of the heat transfer coefficient HTC were computed for the intervals $50-100{ }^{\circ} \mathrm{C}$ of the surface temperatures. The graphs show that the HTC increases with an increase in liquid impingement density and it is possible to say that adding carbon nanotubes and $\mathrm{Fe}$ nanoparticles to pure water decreases HTC in most of researched cases. The HTC was surprisingly 


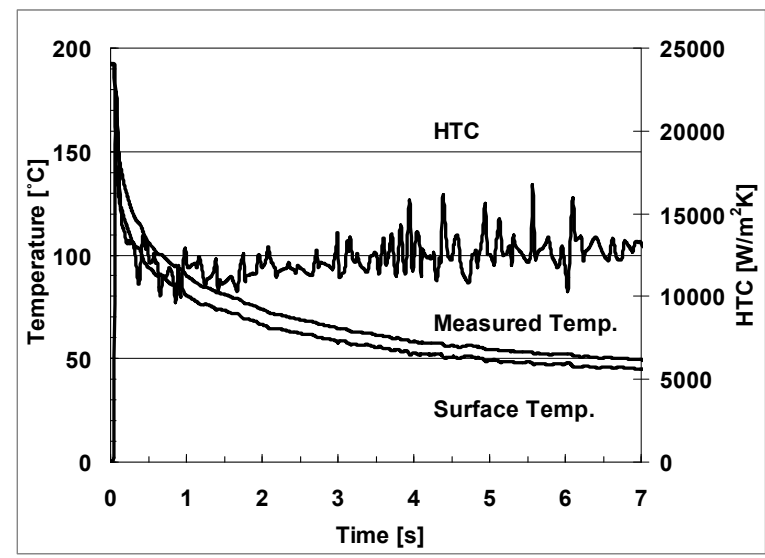

Figure 6: An example of record and results from the cooling experiment with pure water, flow rate of $1.5 \mathrm{~kg} / \mathrm{min}$ and distance between surface and nozzle of $100 \mathrm{~mm}$.

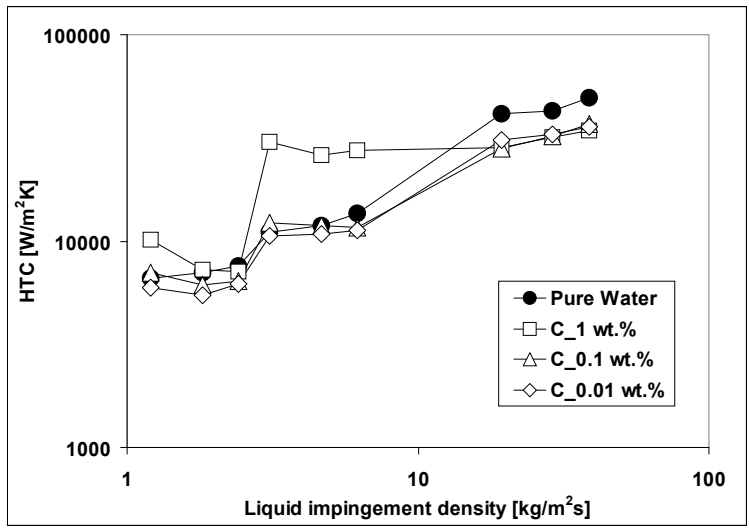

Figure 7: The heat transfer coefficient vs. liquid impingement density for nanofluids with different concentrations of carbon nanotubes.

increased by nanofluid with $1 \mathrm{wt} . \%$ of carbon nanotubes at a distance of $100 \mathrm{~mm}$ (it represents liquid impingement density $3.1 \mathrm{~kg} / \mathrm{m}^{2} \mathrm{~s}, 4.6 \mathrm{~kg} / \mathrm{m}^{2} \mathrm{~s}$ and $6.2 \mathrm{~kg} / \mathrm{m}^{2} \mathrm{~s}$ ). For verification of measurement, the experiments for each nanofluids at a distance of $100 \mathrm{~mm}$ between cooled surface and nozzle and for flow rates of 1 and $2 \mathrm{~kg} / \mathrm{min}$ were provided twice. They are shown in figs. 11 and 12 . 


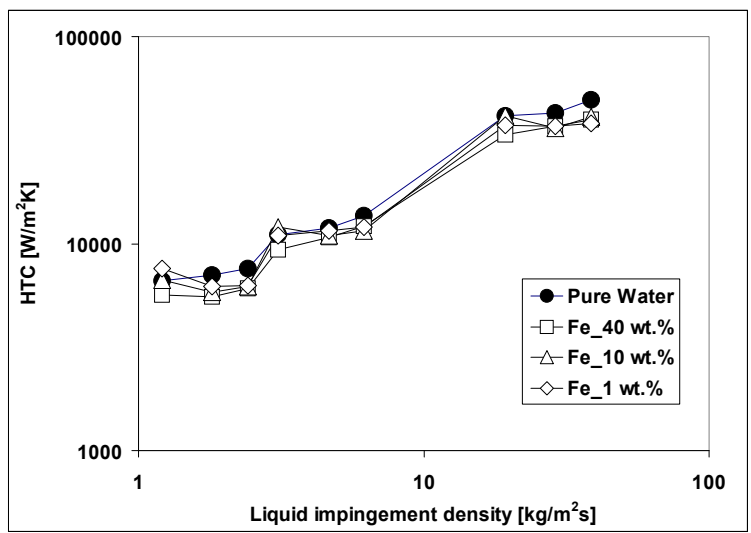

Figure 8: The heat transfer coefficient vs. liquid impingement density for nanofluids with different concentrations of Fe nanoparticles.

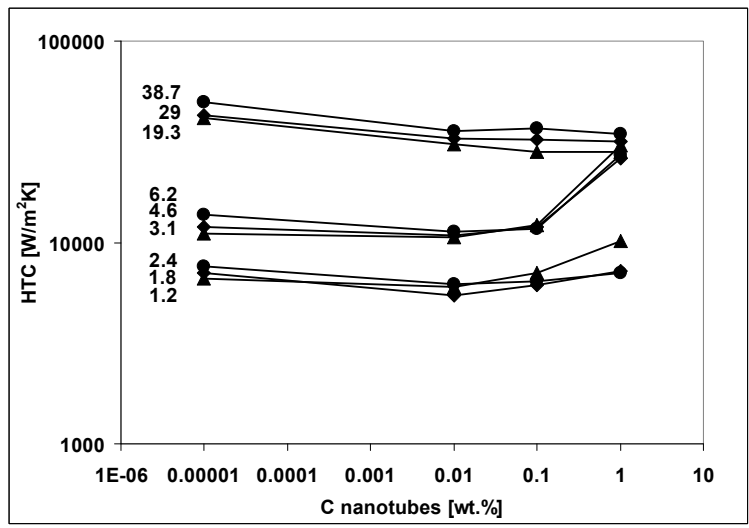

Figure 9: The heat transfer coefficient vs. concentration of carbon nanotubes for variable impingement density shown by the curves with numbers $\left[\mathrm{kg} / \mathrm{m}^{2} \mathrm{~s}\right]$; pure water is shown as nanofluid with $1 \mathrm{e}$ 005 wt. $\%$ of carbon nanotubes. 


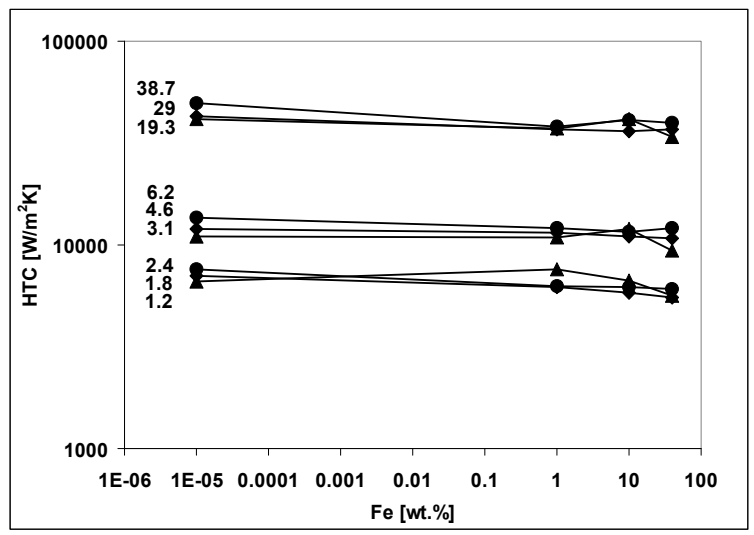

Figure 10: The heat transfer coefficient vs. concentration of Fe nanoparticles for variable impingement density shown by the curves with numbers $\left[\mathrm{kg} / \mathrm{m}^{2} \mathrm{~s}\right]$; pure water is shown as nanofluid with 1e-005 wt.\% of Fe nanoparticles.

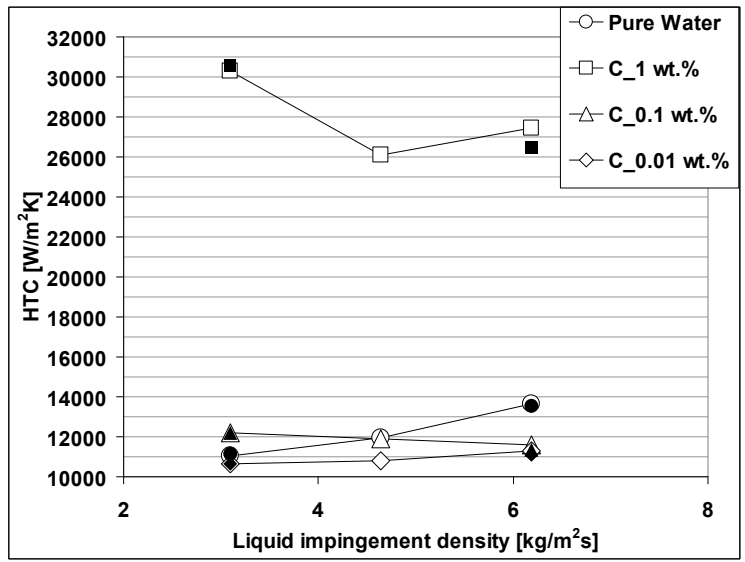

Figure 11: The repeated experiments for nanofluids with carbon nanotubes at a distance of $100 \mathrm{~mm}$ between cooled surface and nozzle; the empty marks represent the first measurements, the filled marks the repeated. 


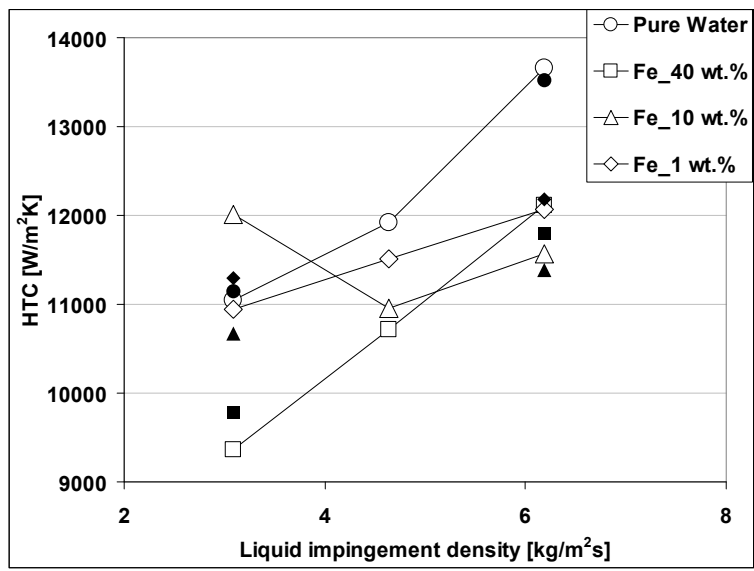

Figure 12: The repeated experiments for nanofluids with Fe nanoparticles at a distance of $100 \mathrm{~mm}$ between cooled surface and nozzle; the empty marks represent the first measurements, the filled marks the repeated.

\section{Conclusions}

Most of the research confirmed an improvement in thermal conductivity and convective heat transfer coefficient during liquid convection by adding carbon nanotubes or $\mathrm{Fe}$ nanoparticles to pure water. This paper investigated spray cooling by these nanofluids. It was found that by adding carbon nanotubes or Fe nanoparticles to pure water the cooling intensity during spraying of the steel surface with its temperatures of 100 to $50{ }^{\circ} \mathrm{C}$ was not increased. A high increase in cooling intensity by spraying only with $1 \mathrm{wt} . \%$ of carbon nanotubes at a distance of $100 \mathrm{~mm}$ from the nozzle was observed. For $3.1 \mathrm{~kg} / \mathrm{m}^{2} \mathrm{~s}$ (flow rate $1 \mathrm{~kg} / \mathrm{min}$ ) the heat transfer coefficient was increased about $174 \%$ to the heat transfer coefficient of pure water, for $4.6 \mathrm{~kg} / \mathrm{m}^{2} \mathrm{~s}(1.5 \mathrm{~kg} / \mathrm{min})$ it was $119 \%$ and for $6.2 \mathrm{~kg} / \mathrm{m}^{2} \mathrm{~s}(2 \mathrm{~kg} / \mathrm{min}) 101 \%$. For other liquid impingement densities a decrease in HTC up to $32 \%, 32 \%, 26 \%$ for nanofluids with $1 \mathrm{wt} . \%, 0.1 \mathrm{wt} . \%$, $0.01 \mathrm{wt} \%$ of carbon nanotubes, respectively, and up to $22 \%, 18 \%, 23 \%$ for nanofluids with $40 \mathrm{wt} . \%, 10 \mathrm{wt} . \%, 1 \mathrm{wt} . \%$ of Fe nanoparticles, respectively, in comparison with pure water was observed. The decrease in HTC was also observed in the work of Bansal and Pyrtle [2] by using alumina nanoparticles in water. Contrary to this the results in Chakraborty's work [1] show an increase in HTC by adding $\mathrm{TiO}_{2}$ nanoparticles. The reason for this could be in the temperature range of the conducted experiments. The experiments carried out for this paper and the Bansal and Pyrtle's experiments [2] were conducted between 200 and $50{ }^{\circ} \mathrm{C}$. However, Chakraborty's research [1] was conducted for temperatures between 1200 and $500{ }^{\circ} \mathrm{C}$. 


\section{References}

[1] Chakraborty, S., Chakraborty, A., Das, S., Mukherjee, T., Bhattacharjee, D. \& Ray, R.K., Application of water base- $\mathrm{TiO} 2$ nano-fluid for cooling of hot steel plate. ISIJ International, 50, pp. 124-127, 2010.

[2] Bansal, A. \& Pyrtle, F., Alumina nanofluid for spray cooling enhancement. ASME-JSME Thermal Engineering Summer Heat Transfer Conference, pp. 797-803, 2007.

[3] Choi, S.U.S., Zhang, Z.G., Lockwood, F.E. \& Grulke E.A., Anomalous thermal conductivity enhancement in nanotubes suspensions. Physics Letters, 79, pp. 2252-2254, 2001.

[4] Assael, M.J., Chen, C.F., Metala, I. \& Wakeham, W.A., Thermal conductivity of suspensions of carbon nanotubes in water. International Journal of Thermophysics, 25, pp. 971-985, 2004.

[5] Amrollahi, A., Hamidi, A.A. \& Rashidi, A.M., The effects of temperature, volume fraction and vibration time on the thermo-physical properties of a carbon nanotube suspension (carbon nanofluid). Nanotechnology, 19 (31), pp. 1-8, 2008.

[6] Zhu, H., Zhang, C., Liu, S., Tang, Y. \& Yin, Y., Effect of nanoparticle clustering and alignment on thermal conductivities of $\mathrm{Fe} 3 \mathrm{O} 4$ aqueous nanofluids. Applied Physics Letters, 89, article number 023123, 2006.

[7] Hong, K.S., Hong, T.K. \& Yang, H.S., Thermal conductivity of Fe nanofluids depending on the cluster size of nanoparticles. Applied Physics Letters, 88, articles number 031901, 2006.

[8] Ding, Y., Alias, H., Wen, D. \& Williams, R.A., Heat transfer of aqueous suspensions of carbon nanotubes (CNT nanofluids). Heat and Mass Transfer, 49, pp. 240-250, 2006.

[9] Liao, L. \& Liu, Z.H., Forced convective flow drag and heat transfer characteristics of carbon nanotube suspensions in a horizontal small tube. Heat and Mass Transfer, 45, pp. 1129-1136, 2009.

[10] Park, K.J. \& Jung, D.S., Enhancement of nucleate boiling heat transfer using carbon nanotubes. Heat and Mass Transfer, 50, pp. 4499-4502, 2007.

[11] Park, K.J., Jung, D. \& Shim, S.E., Nucleate boiling heat transfer in aqueous solutions with carbon nanotubes up to critical heat fluxes. International Journal of Multiphase Flow, 35, pp. 525-532, 2009.

[12] Shi, M.H., Shuai, M.Q., Li, Q. \& Xuan, Y.M.: Study on pool boiling heat transfer of nano-particle suspensions on plate surface. Journal of Enhanced Heat Transfer, 14, pp. 223-231, 2007.

[13] Beck, J., Blackwell, B. \& Clair, C.R., Inverse Heat Conduction, Wiley, 1985.

[14] Ciofalo, M., Caronia, A., Di Liberto, M. \& Puleo, S. The Nukiyama curve in water spray cooling: Its derivation from temperature-time histories and its dependence on the quantities that characterize drop impact. Heat and Mass Transfer, 50, pp. 4948-4966, 2007. 